\title{
Analysis of the relationship between life expectancy and social determinants in a north-eastern region of Brazil, 2010-2017
}

\author{
Andrezza Marques Duque, ${ }^{1,7}$ Marcus Valerius Peixoto, ${ }^{2}$ Shirley V.M.A. Lima, ${ }^{3}$ Marco Aurélio O. \\ Goes, ${ }^{4}$ Allan D. Santos, ${ }^{3,5}$ Karina Conceição Gomes Machado Araújo, ${ }^{6,7}$ Marco Antonio P. Nunes ${ }^{4,7}$ \\ ${ }^{1}$ Department of Occupational Therapy; ${ }^{2}$ Department of Speech Therapy; ${ }^{3}$ Department of Nursing; \\ ${ }^{4}$ Department of Medicine; ${ }^{5}$ Post-Graduate Program in Nursing; ${ }^{6}$ Department of Morphology; \\ ${ }^{7}$ Post-Graduate Program in Health Sciences, Federal University of Sergipe, Sergipe, Brazil
}

\begin{abstract}
The process of population aging is a worldwide reality becoming a global public health challenge. Although population aging is especially noticeable in more developed regions, there has also been a significant advance in the quantity of elderly people in
\end{abstract}

\footnotetext{
Correspondence: Karina Conceição Gomes Machado Araújo, PostGraduate Program in Health Sciences, Federal University of Sergipe, Av. Marechal Rondon, s/n, Jd. Rosa Elze, São Cristóvão, SE, 49100-000, Sergipe, Brazil.

E-mail: Kkkaraujo2006@yahoo.com.br
}

Key words: Aging; Epidemiology; Geographic information systems; Spatial analysis; Brazil.

Contributions: AMD and MAPN formulated the idea, participated in the analysis and interpretation of the data and the preparation of the manuscript. MVSP collaborated for spatial analysis, data interpretation and literature review. SVMAL, MAOG, KCGMA and ADS contributed to spatial analysis and interpretation of data. All authors contributed to discuss the content and writing of the manuscript.

Conflict of interest: the authors declare no potential conflict of interest.

Funding: none.

Availability of data and material: the datasets generated and/or analysed during the current study are available in the Brazilian Demographic Census [http://censo2010.ibge.gov.br], the Institute of Applied Economic Research [www.ipeadata.gov.br/default.aspx], and the Department of Informatics of the Unified Health System [http://datasus.saude.gov.br/informacoes-de-saude].

Received for publication: 24 April 2018

Revision received: 9 October 2018.

Accepted for publication: 9 October 2018.

(C) Copyright A.M. Duque et al., 2018

Licensee PAGEPress, Italy

Geospatial Health 2018; 13:702

doi:10.4081/gh.2018.702

This article is distributed under the terms of the Creative Commons Attribution Noncommercial License (CC BY-NC 4.0) which permits any noncommercial use, distribution, and reproduction in any medium, provided the original author(s) and source are credited. areas with unfavourable socioeconomic indicators, and a rapid growth in countries with a low level of economic development. This article presents an analysis based on spatial autocorrelation of the relationship between life expectancy and social determinants in a north-eastern region of Brazil. An ecological study was conducted using the secondary data of social, demographic, and health indicators of elderly people collected in the Brazilian Demographic Census of the 75 municipalities of the state of Sergipe. Spatial autocorrelation was evaluated using the Moran global index and the local indicators of space association. Multiple linear regression models were used to identify the relationship between life expectancy and social determinants. The South-eastern region of the state presented clusters with all indicators pointing to acceptable lifestyles, whereas the municipalities of the north-western and far-eastern regions were characterized by values demonstrating precarious living conditions. The high dependency ratio, illiteracy rate, and unemployment rate among elderly people had a negative impact on life expectancy. The evidence confirms that there is an autocorrelation between social determinants and life expectancy, indicating that the worse the social, economic, and health indicators are, the lower the life expectancy. This finding indicates the need to redirect public policies and formulate strategies aimed at reducing social and health inequalities.

\section{Introduction}

Population aging may well be the next global public health challenge (Suzman et al., 2015). In Brazil, this process presents specific problems related to the speed with which it is growing and the appearance of various social and health impacts that must be addressed (Carvalho and Rodríguez-Wong, 2008; Veras, 2009; Rede Interagencial de Informações para Saúde, 2009). Although population aging is especially noticeable in more developed regions, the quantity of elderly people has also increased in areas with unfavourable socioeconomic indicators, such as countries with low levels of economic development (Marmot, 2005; Veras, 2009).The epidemiological and demographic changes that have intensified population aging over time have not occurred equally in society. The challenge imposed by this new reality demands action in the economic, political, social, and health spheres (Rodrigues and Neri, 2012; Bloom et al., 2015; Rasella et al., 2016) in order to guarantee elderly people an autonomous and independent lifestyle, especially in view of the inequalities to which the Brazilian elderly population are currently subjected (Rodrigues and Neri, 2012).

In recent decades, there has been a breakthrough in the study 
of the relationships of in equalities and social inequities with health outcomes (Clarke et al., 2010; Geib, 2012; Kolahdooz et al., 2015; Sudharsanan, 2017). It should be noted that these inequalities are accentuated in middle- and lower-income countries, wherein the life expectancy is increasing rapidly (Lima-Costa et al., 2012). It is also worth mentioning the need to include information about the social determinants of health in the formulation of public policies (Rasella et al., 2016), especially considering that socioeconomic factors are the first to influence individual health (Clarke et al., 2010; Geib, 2012). Exposure to social disadvantage in childhood predisposes to health risks throughout life, which in turn might result in fragility in aging (Kinge et al., 2015).

Marmot (2005) and Bloom et al. (2015) have reported that health inequalities lead to very unequal life expectancy between different countries: for instance, Sierra Leone has a life expectancy at birth of 34 years, whereas Japan has one of about 82 years. They also point out that there are also similar differences within countries. In Brazil, data from the latest survey by the Brazilian Institute of Geography and Statistics (Instituto Brasileiro de Geografia e Estatística, 2010) reveals that life expectancy varies between the Brazilian states, e.g., the difference between Maranhão and Santa Catarina is 70.3 and 78.7 years, respectively. However, the greatest disparities are evident when comparing urban and rural areas. Thus, it is reasonable to say that the Brazilian socioeconomic context exposes an unjust and unequal country (Geib, 2012). However, important improvements have occurred over the last decade with reference to living conditions and health status. During this period, the country experienced a period of economic growth as a result of better income distribution as well as a reduction in social inequalities and extreme poverty (Lima-Costa et al., 2012; Rasella et al., 2016). Furthermore, the average education level has improved, illiteracy rates and the Gini coefficient (a measure of income inequality) have decreased and income transfer, e.g., the Bolsa Familia's benefit programme for families, has contributed to economic growth. All of this has been accompanied by an improvement in living conditions for the poorest sectors of the population (Estatuto do Idoso, 2013; Rasella et al., 2016).

It is believed that life expectancy is influenced by social, economic and health indicators. In this context, it is necessary to investigate the social and economic conditions that interfere with life expectancy at birth. It is also necessary to identify and monitor aspects related to the care of elderly people. Based on this thinking, this study aimed to analyze spatial autocorrelation and the relationship between life expectancy and social determinants in a region of north-eastern Brazil. This is then an ecological study using spatial analysis techniques with areal data.

\section{Materials and Methods}

\section{Data and variables}

The units of analysis were the 75 municipalities of the state of Sergipe, in the Northeast of Brazil. Sergipe has an area of $21,915.16 \mathrm{~km}^{2}$ and a population of 2,068,017 inhabitants with $8.9 \%(185,957) 60$ years of age or older (Instituto Brasileiro de Geografia e Estatística, 2010). In this analysis, elderly people were considered those aged 60 years or over, which follows the Brazilian Elderly Statute (Estatuto do Idoso, 2013).

Secondary data of social, demographic and health indicators from the Brazilian Demographic Census (Instituto Brasileiro de
Geografia e Estatística, 2010), the Institute of Applied Economic Research (Instituto de Pesquisa Econômica Aplicada, 2017) and the Department of Informatics of the Unified Health System (DATASUS, 2017) were analyzed. The data referred to the resident population of the municipalities of the state of Sergipe. In addition, the variable of life expectancy also called life expectancy at birth was used. This variable refers to the average number of years of life expected for a newborn and maintains the existing mortality pattern in the resident population in a given geographic area in the year considered (Instituto Brasileiro de Geografia e Estatística, 2010).

The identification of inequalities in the socio-spatial profile of the state was conducted using the socioeconomic indicators of the municipalities, which are represented graphically by thematic maps. To evaluate the possible associations between socioeconomic conditions and life expectancy, 11 independent variables were analyzed. These included the socioeconomic variables of the dependency ratio: average household income per capita, percentage of the population with a per capita income of up to one-quarter of the minimum wage, gross domestic product (GDP) per capita, the unemployment rate of the population aged 16 years or over and the illiteracy rate among elderly people; variables related to the municipalities' infrastructure: the percentage of households with a water supply not connected to the distribution network and the percentage of households without a garbage collection service; variables related to the access to health care: the rate of primary care visits and the rate of consultations with elderly people in primary care; and a variable related to the access to income transfer programs, which was the rate of elderly people receiving continuous benefits.

\section{Statistics}

The determination of existence or not of a spatially conditioned standard between life expectancy and social determinants was made using the Moran's global index (I) (Moran, 1948) to identify clusters of areas with similar risks for the occurrence of the outcome of interest. This index can detect the existence of spatial patterns; that is, the similarity between areas. A neighbourhood matrix was constructed using the criterion of border contiguity among the 75 municipalities in the state adopting a level of significance of 5\%. The statistical significance of the autocorrelation (Pvalue) is also provided. Values close to zero indicate spatial randomness, positive values indicate positive spatial autocorrelation and negative values indicate negative spatial autocorrelation meaning that significance values lower than 0.05 delimit regions where there are local spatial structures.

The global Moran autocorrelation coefficient is based on the cross-products of the deviations from the mean calculated for $n$ observations as follows (Moran, 1948) (Eq. 1):

$$
\mathrm{I}=\frac{\left[\left(\mathrm{n} \Sigma_{\mathrm{i}}^{\mathrm{n}} \Sigma_{\mathrm{j}}^{\mathrm{n}} \omega_{\mathrm{ij}}\left(\mathrm{y}_{\mathrm{i}}-\overline{\mathrm{y}}\right)\left(\mathrm{y}_{\mathrm{j}}-\overline{\mathrm{y}}\right)\right]\right.}{\left[\Sigma_{\mathrm{i}}^{\mathrm{n}}\left(\mathrm{y}_{\mathrm{i}}-\overline{\mathrm{y}}\right)^{2} \Sigma_{\mathrm{i}}^{\mathrm{n}} \sum_{\mathrm{j}}^{\mathrm{n}} \omega_{\mathrm{ij}}\right]}
$$

where $\omega_{i j}$ is the element of the $\omega$ contiguity matrix; $y_{i}$ is the area indicators of the municipality $i ; y_{j}$ is the area indicators of the municipality $j ; \bar{y}$ is the mean of the indicators, and $n$ represents the total number of cities.

In the next step, the local indicators of spatial association (LISA) were applied to detect regions with significant local spatial 
autocorrelations $(\mathrm{P}<0.05 \%)$. The LISA (Moran, 1948) is a very useful statistical tool, which is defined as the product of the residue in the reference polygon. The local mean of the residues of its adjacent neighbours are used to generate maps indicating regions with local autocorrelations significantly different from those of other regions, thereby identifying clusters and outliers (Ministério da Saúde, Brasil, 2007) (Eq. 2).

$$
\mathrm{I}=\frac{\mathrm{n}\left[\left(\mathrm{Z}_{\mathrm{i}} \Sigma_{\mathrm{j}}^{\mathrm{n}} \omega_{\mathrm{ij}} \mathrm{Z}_{\mathrm{j}}\right.\right.}{\left(\Sigma_{\mathrm{j}}^{\mathrm{n}} \mathrm{Z}_{\mathrm{j}}^{2}\right)}
$$

Investigation of the spatial variability behaviour was done by Moran's scatterplot, which compares the normalized values of an attribute in an area with the mean of its neighbours and constructs a two-dimensional graph of $z$ (normalized values) by $W_{z}$ (the mean of the neighbours). The resulting graph has four quadrants, in which Q1 and Q2 indicate positive associations, i.e. high-high and low-low points, respectively, whileQ3 and Q4 indicate negative associations, i.e. high-low and low-high points, respectively. The Moran map was constructed to illustrate the regions that present spatial dependence with significant values $(\mathrm{P}<0.05)$. For the inferential analysis, a multiple linear regression model was developed, taking into account life expectancy as the dependent variable and all other determinants as the independent variables. The ShapiroWilk test (Shapiro and Wilk, 1965) was used to evaluate the distribution of the normality of the variables considering 0.05 as the level of significance. Logarithmic transformation of the independent variables was performed in order to prevent a small number of extraordinarily large or small observations from having an undue influence on the sum of the squares of the predictive model errors. The spatial analyses were performed using the TerraView4.2.2 software (Informer Technologies, São José dos Campos, São Paulo, Brazil) and QGIS2 v.18.3 software (Creative Commons Attribution-Share Alike 3.0 license CC BY-SA, Las Palmas, CA, USA). The inferential statistical analysis was performed using R software version 3.3.0 (R Core Team, Vienna, Austria).

\section{Results}

The spatial distribution of life expectancy indicated that there was only one municipality (the state capital) with a value compatible with the Brazilian average (73.9 years) and 15 municipalities with the state average ( 71.8 years). It should be noted that $80 \%$ $(60 / 75)$ of the municipalities exhibited values below the regional and Brazilian average, suggesting worse living conditions and worse health (Figure 1A).

The analysis of the maps allowed the identification of groupings of municipalities with similar behaviour in relation to the life expectancy. The observation with the global Moran's I showed that there was a statistically significant spatial correlation $(0.361, \mathrm{P}$ value 0.01 ), indicating that areas with similar life expectancies, in general, are closer to each other than other areas.

The identification of clusters based on LISA generated the Moran map shown in Figure 1B. The results indicated regions exhibiting significant local spatial autocorrelations. The life expectancy map confirmed the aggregates that had better or worse means, with the presence of clusters in the south-eastern and northeastern regions, respectively. In the former, which is closer to the state capital, there were areas with positive values (Q1), whereas in the extreme East, the opposite occurred, i.e. areas with negative values (Q2). A few transitional areas that did not follow the same process of spatial dependence as the others were observed in the Q3 quadrant.

Table 1 shows the existence of a statistically significant spatial autocorrelations in nine of the 11 independent variables used, with positive values indicating direct autocorrelations. Using the local Moran's $I$, it was possible to identify the social determinants with significant spatial autocorrelations. There were clusters in three main regions (Figure 2): one in the metropolitan region of the state with the highest incomes per household (B), higher unemployment rates $(\mathrm{E})$, lower dependency ratios $(\mathrm{A})$ and lower rates of illiteracy in the elderly $(\mathrm{F})$; another in the high backwoods region with the strongest indicators of poverty $(\mathrm{C})$, illiteracy among the elderly (F) and low coverage of primary care $(\mathrm{H})$; and one region of poverty (C) in the eastern end.

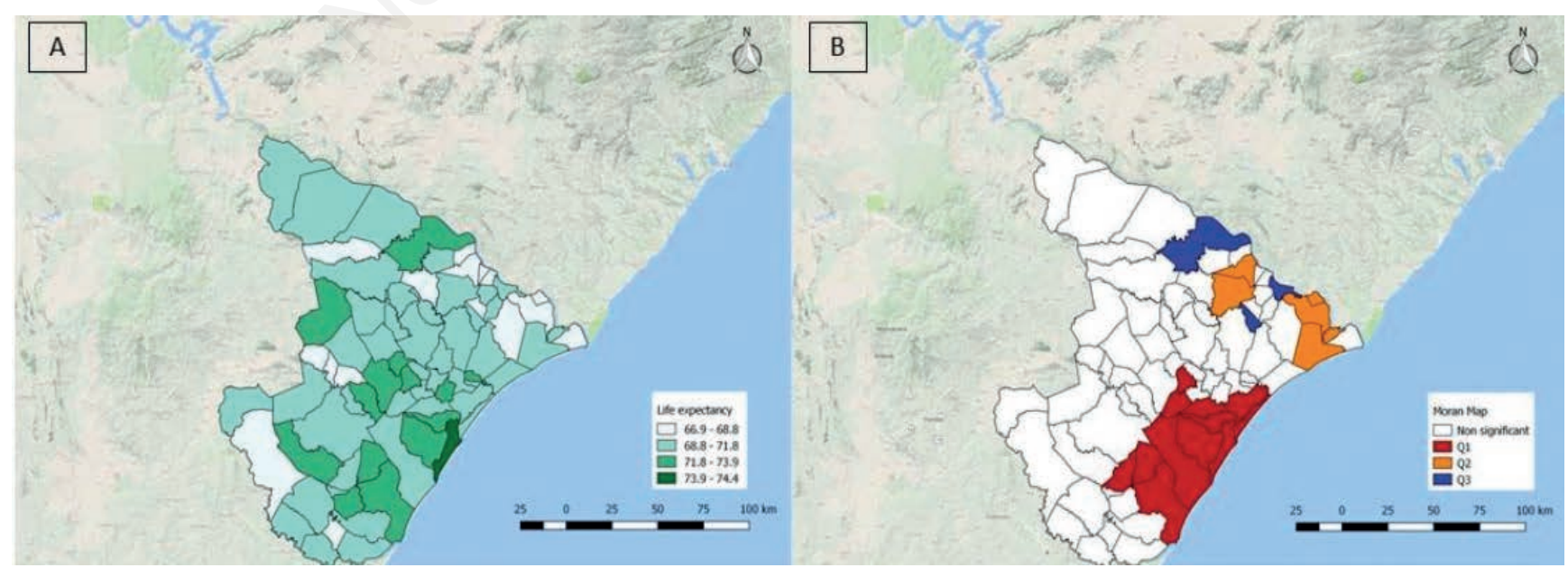

Figure 1. Life expectancy in municipalities of a north-eastern region of Brazil, 2010. (A) Distribution of life expectancy; (B) Moran map of life expectancy. 
The descriptive exploratory analysis of the data is presented in Table 2. Because of the skewness, median, and quartiles variables are described. In the regression model, a strong negative correlation $(r:-0.670)$ was observed between the following two variables: the average household income per capita and the percentage of the population with per capita income up to one quarter of the minimum wage. In the multidimensional model only those variables that were not strongly linearly correlated were included, so the mean per capita household income variable was excluded. A high Fstatistic and a significant P-value (i.e. lower than 0.05) were found. The results of the model indicate that a high dependency ratio, illiteracy rate, and unemployment rate have statistically significant negative impacts on life expectancy (Table 3 ).
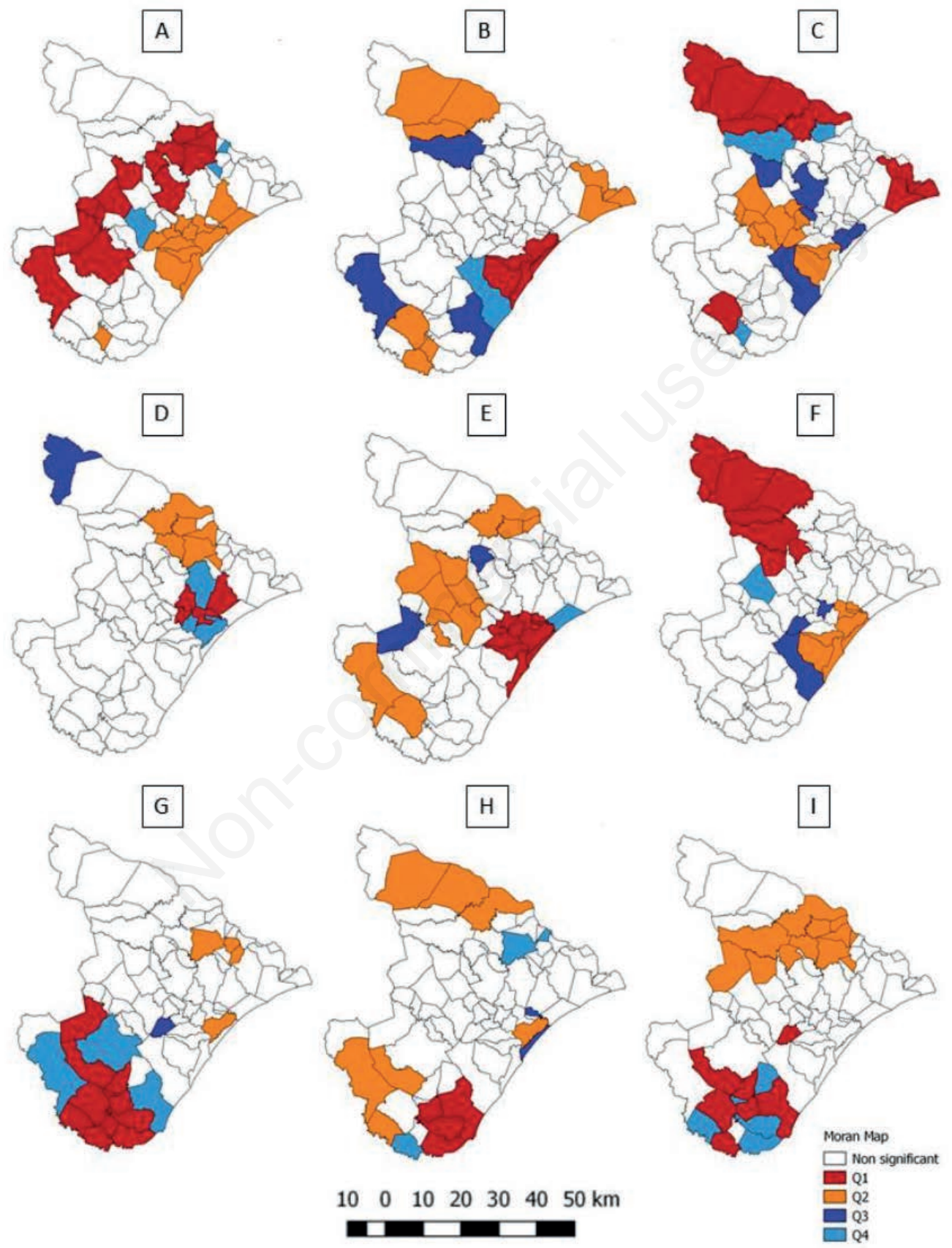

Figure 2. Moran map of the social determinants in the municipalities of a north-eastern region of Brazil, 2010. (A) Dependency ratio; (B) Average household income per capita; (C) Population with per capita income up to one quarter of the minimum wage; (D) Gross domestic product per capita; (E) Unemployment rate of the population aged 16 years or over; (F) Illiteracy rate among the elderly; (G) Households with water supply not connected to the distribution network; (H) Rate primary care visit; (I) Rate of the elderly who received benefit of the continuous benefit. 
Table 1. Spatial correlation among the social determinants of municipalities in a north-eastern region of Brazil, 2010.

\begin{tabular}{llc} 
Social determinant & $I^{*}$ & P-value \\
Life expectancy & 0.476 & 0.001 \\
Dependency ratio & 0.205 & 0.025 \\
\hline Illiteracy rate among the elderly & 0.482 & 0.001 \\
Average household income per capita & 0.133 & 0.046 \\
\hline Population with per capita income up to one quarter of the minimum wage (\%) & 0.529 & 0.001 \\
Unemployment rate of the population aged 16 years or over & 0.388 & 0.001 \\
\hline Gross domestic product** per capita & 0.449 & 0.001 \\
Households with a water supply not connected to the distribution network (\%) & -0.020 \\
\hline Households without garbage collection service (\%) & 0.132 & 0.427 \\
Rate of primary care visits & 0.098 & 0.013 \\
\hline Rate of consultations with elderly people in primary care & 0.224 & 0.119 \\
\hline
\end{tabular}

*Moran's global index; **Values in USD.

Table 2. Descriptive statistics of the social determinants of a north-eastern region of Brazil, 2010.

\begin{tabular}{|c|c|c|c|c|c|c|}
\hline Variable & Minimum & Q1* & Median & $I_{Q} R^{* *}$ & Q3* & Maximum \\
\hline Life expectancy & 66.9 & 68.9 & 70.6 & 2.7 & 71.5 & 74.4 \\
\hline Dependency ratio & 7.7 & 13.9 & 15.7 & 3.9 & 17.7 & 21.6 \\
\hline Illiteracy rate among the elderly & 18.2 & 54.0 & 60.2 & 11.5 & 65.5 & 78.8 \\
\hline Average household income per capita & 185.6 & 247.4 & 277.3 & 70.1 & 317.5 & $1,022.1$ \\
\hline Population with per capita income up to one quarter of the minimum wage (\%) & 12.9 & 30.0 & 33.7 & 11.1 & 41.1 & 58.7 \\
\hline Unemployment rate of the population aged 16 years or over & 2.2 & 5.9 & 8.2 & 6.0 & 11.8 & 29.4 \\
\hline Gross domestic product*** per capita & $4,739.1$ & $6,241.0$ & $7,507.2$ & $3,419.4$ & $9,660.4$ & $67,568.7$ \\
\hline Households with a water supply not connected to the distribution network (\%) & 0.7 & 8.4 & 14.9 & 13.4 & 21.7 & 44.0 \\
\hline Households without garbage collection service (\%) & 0.0 & 0.8 & 1.8 & 2.7 & 3.5 & 14.9 \\
\hline Rate of primary care visits & 0.6 & 1.3 & 2.0 & 1.2 & 2.5 & 4.3 \\
\hline Rate of consultations with elderly people in primary care & 2.2 & 3.4 & 3.9 & 1.2 & 4.7 & 11.8 \\
\hline Rate of elderly people receiving a continuous benefit & 0.0 & 0.0 & 0.0 & 0.1 & 0.1 & 0.2 \\
\hline
\end{tabular}

${ }^{*}$ quadrant $1 ; *$ interquartile range; $* * *$ Values in USD.

Table 3. Multivariate linear regression model of the social determinants of a north-eastern region of Brazil, 2010.

\begin{tabular}{|c|c|c|c|c|}
\hline & Coefficient & $\mathrm{SE}^{*}$ & t-value & P-value \\
\hline (Intercept) & 91.710 & 6.046 & 15.169 & $<0.001$ \\
\hline Dependency ratio & -0.172 & 0.083 & -2.081 & 0.042 \\
\hline Illiteracy rate among the elderly & -2.906 & 1.207 & -2.408 & 0.019 \\
\hline Average household income per capita & -0.040 & 0.023 & -1.696 & 0.095 \\
\hline Population with per capita income up to one quarter of the minimum wage (\%) & -0.940 & 0.461 & -2.037 & 0.046 \\
\hline Unemployment rate of the population aged 16 years or over & -0.233 & 0.413 & -0.565 & 0.574 \\
\hline Gross domestic product per capita** & 0.252 & 0.280 & 0.901 & 0.371 \\
\hline Households with a water supply not connected to the distribution network (\%) & -0.038 & 0.063 & -0.615 & 0.541 \\
\hline Households without garbage collection service (\%) & 0.350 & 0.485 & 0.721 & 0.474 \\
\hline Rate of primary care visits & -0.917 & 0.637 & -1.440 & 0.155 \\
\hline Rate of consultations with elderly people in primary care & 0.259 & 0.251 & 1.032 & 0.306 \\
\hline
\end{tabular}




\section{Discussion}

The pattern of the spatial distribution of the life expectancy of the elderly residents in the region analysed showed that there was a predominance of municipalities with rates falling short of the life expectancy in the more developed regions. As observed, these low values were not random and the thematic maps show that the heterogeneity in the distribution of life expectancy is related to the spatial profile of the social determinants. The areas located in the Southeast of the state, close to the metropolitan region, presented the highest values of the socioeconomic indicators for life expectancy, while the areas located in the extreme East and Northwest, in the region of Sertao, showed values indicating a worse economic and social situation correlating with lower life expectancy. Because the regions that presented the lowest socioeconomic indicator values also had lower values of life expectancy it can be concluded that socioeconomic factors exert a strong influence on life expectancy.

The data confirm that there is a greater life expectancy in the metropolitan region, where the income indicators are higher and where people live in less extreme poverty. Low life expectancy in the state is associated with the strongest poverty rates, which was indicated by the clusters formed in the north-western and eastern regions. The metropolitan region has greater occupation due to the urban infrastructure as well as the availability of various services and economic and employment opportunities (Rivera-Hernandez et al., 2015). In addition, the growth of the population in these places may be due to urbanization and the migratory process (Rivera-Hernandez et al., 2015). In Brazil, migration from rural to urban areas typically occurs because of the supply of goods and services.

Several studies have pointed out that income has an effect on life expectancy (Lin et al., 2012; Mondal and Shitan, 2014; Mathers et al., 2015; Marmot, 2016). In high-income countries, life expectancy has increased in recent decades (Mathers et al., 2015; Suzman et al., 2015). On the other hand, there is evidence of the association of income inequality with the inferiorhealth conditions; therefore, in low- and middle-income countries, lower life expectancy may be related to lower expenditure on preventive medicine and health care. This has important implications because economic difficulties can affect the most vulnerable populations, such as the elderly (Mondal and Shitan, 2014). Furthermore, Lin et al. (2012) demonstrated that gains in life expectancy can more be attributed to improvement in the economy than to literacy, malnutrition or the political regime, and that shows that progress in economic status can also have a positive effect on life expectancy that can last for several years.

In the metropolitan cluster, which had the best life expectancy rate, there was a spatial autocorrelation between life expectancy and a lower degree of economic dependence because the region has a larger economically active population. Despite this, there is a higher unemployment rate, which was probably created by the high reserves of workers linked to migration. This could have contributed to the formation of unemployed people of productive age. The results of the multivariate regression also showed an inversely proportional correlation between life expectancy and dependence ratio in the state, mainly due to unemployment. The decrease in the dependence ratio may be related to the demographic transition phenomenon associated with the reduction of fertility rates in the region. The data indicate that the regions with high values of the dependency ratio have a population of dependents that is higher than in the productive population, which means an increase in welfare costs for society (Saude, 2012). As described by Bloom et al. (2015), the public pension expenditure in Brazil is equal to $13 \%$ of the GDP, reflecting the need for reform, such as that conducted in the UK, given the ability and need of each country. The GDP per capita did not present itself as a good indicator of a social determinant of health, because it can suffer bias from the social differences resulting from the concentration of income, which is demonstrated by the fact that the municipality that has the highest GDP per capita is the same one that has the larger poverty rate. Thus, it seems reasonable to state that just as rich countries show little relationship between GDP and life expectancy (Marmot, 2005) in poor regions. Indeed, no such relationship was found in the current study. Education is another factor that affects life expectancy (Mondal and Shitan, 2014; Kinge et al., 2015). In accordance with these studies, the multivariate regression showed an inverse correlation between life expectancy and illiteracy as well as a spatial autocorrelation between life expectancy and illiteracy among the elderly. Two clusters were formed: one in the metropolitan region and one in the north-western region. The metropolitan region had a better life expectancy and lower illiteracy rate, while the northwestern one showed the lowest rates for both indicators, something that was reinforced by the overlap between illiteracy in the elderly and poverty with life expectancy. This has important implications because a low level of attendance to primary schooling compromises access to education and leads to less health awareness, which may interfere with the adoption of healthy behaviours and social mobilization to improve quality of life (Geib, 2012; Mondal and Shitan, 2014). Therefore, it is incumbent upon public managers to seek strategies in the formulation of actions aimed at reducing illiteracy because, as highlighted by Rasella et al. (2016), illiteracy and poverty rates are higher in the northern and northeastern regions of Brazil where life expectancy also reach the lowest rates.

The existence of a spatial autocorrelation between primary care visit rates and low life expectancy that was strongly indicated in the north-western region of the state, which suggests that social inequalities in access to, and use of, health services still persist there. It should be noted that, although the association between health service consultation and life expectancy is weak, the slow decrease in mortality among the elderly in middle-income countries is related to several factors, including lower coverage of primary and secondary health care (Mathers et al., 2015). Valentine and Bonsel (2016) argue that health facilities and access to services for disadvantaged groups may also be the result of a lack of transportation and longer journeys in rural areas. Although controversial, there has been progress in recent years in Brazil in terms of public policies for better access to primary health care services, particularly for the poorest, through the Family Health Program, especially in rural and poor areas (Andrade et al., 2013).

The population base together with the representativeness and quality of the data documented in the main Brazilian survey, were seen as the main advantages when we undertook this study. However, the low variability of some indicators in the units of analysis could be minimized by, for example, observing smaller analysis units with census tracts. One fact to be highlighted is the differences between the municipalities of the state because, on the one hand, there are large rural areas with a scarcity of water and sanitation services, and on the other, areas that are advanced with respect to the urbanization process, which contributes to the proliferation of precarious living conditions and unhealthy housing. 
Nevertheless, the choice made in this research does not make the analyses or the relevance of the results unfeasible, and we feel that the study should be replicated in different regions.

As shown by using different social determinants, it was possible to identify that health conditions are directly related to the economic and social conditions, because the worse the economic and social conditions, the lower the life expectancy. It is known that economic development determines improvement in social conditions and increases people's life expectancy (Mondal and Shitan, 2014). Thus, a social policy is crucial for reducing both health inequalities (Marmot, 2005)and the lack of investment in health because it may harm the economic performance of countries (Bloom et al., 2015). European countries have revised their policies by identifying how to address the social determinants of health, and have subsequently implemented measures to improve health and reduce inequities in order to protect disadvantaged populations from exposure and vulnerabilities linked to their economic position (Marmot, 2005; Geib, 2012). In Brazil, improvements can be attributed to economic growth as well as social and health policies, such as the expansion of the Unified Health System and improvements in access to health care, especially primary care (Rasella et al., 2016). Although Brazil has made great progress and been able to keep up with the social and health conditions of developed countries (Rasella et al., 2016), principally through the reduction of inequalities and poverty, the benefits have not been equally enjoyed by all regions (Andrade et al., 2013). Thus, inequalities in health between and within countries should be avoidable, as there is no biological reason for differences in life expectancy, and it is essential to reduce health inequalities, increase disease control, improve health systems and increase efforts to address poverty (Marmot, 2005).

\section{Conclusions}

Although Brazil has presented improvements in socioeconomic and health conditions, the situation is still serious. There are great inequities in the distribution of wealth, and there are large sectors of the population living in conditions of poverty that do not allow them access to minimum conditions and essential goods. This situation was clearly evident in this study with regard to the interregional differences within Brazil.

Considering that the increase in life expectancy is one of the greatest achievements by society in Brazil and the world, the results described here indicate the need to redirect public policies with a view to reducing social and health inequalities following the example of developed countries in order to formulate strategies regarding the challenges of the economic and social conditions that developing regions still face.

The findings presented here demonstrate the spatial dependence between social determinants and their influence on life expectancy. Clusters were identified in the south-eastern region of the state, where the metropolitan region was found to be characterized by the best social indicators and life expectancy, while in the north-western and far-eastern regions, the social indicators and life expectancy were at low values reflecting the precarious living conditions prevailing there. In addition, the analysis of the model allowed us to identify that a high dependency ratio and illiteracy rate in the elderly together with a high unemployment rate have a negative impact on life expectancy.

\section{References}

Andrade MV, Noronha KVM de S, Menezes R de M, Souza MN, Reis C de B, Martins DR, Gomes L, 2013. Desigualdade socioeconômica no acesso aos serviços de saúde no Brasil: um estudo comparativo entre as regiões brasileiras em 1998 e 2008. Econ Apl 17:623-45.

Bloom DE, Chatterji S, Kowal P, Lloyd-Sherlock P, McKee M, Rechel B, Rosenberg L, Smith JP, 2015. Macroeconomic implications of population ageing and selected policy responses. Lancet 385:649-57.

Carvalho JAM de, Rodríguez-Wong LL, 2008. A transição da estrutura etária da população brasileira na primeira metade do século XXI. Cad Saude Publica 24:597-605.

Clarke CA, Miller T, Chang ET, Yin D, Cockburn M, Gomez SL, 2010. Racial and social class gradients in life expectancy in contemporary California. Soc Sci Med 70:1373-80.

DATASUS, 2017. Department of Informatics of the Unified Health System. Available from: http://datasus.saude.gov.br/informacoes-de-saude Accessed: May 16, 2017.

Estatuto do Idoso, 2013. 3rd ed. Brasília-DF, Brazil: Ministério da Saúde. Available from: www.saude.gov.br/editora

Fichas de Qualificação, 2012. Razão de dependência - A.16 2012. Available from: fichas.ripsa.org.br/2012/a-16/?I=pt_BR Accessed: May 16, 2017.

Geib LTC, 2012. Determinantes sociais da saúde do idoso Social. Ciência Saúde Coletiva 17:123-33.

Instituto Brasileiro de Geografia e Estatística, 2010. Censo Demográfico. Available from: http://censo2010.ibge.gov.br Accessed January 18, 2017.

Instituto de Pesquisa Econômica Aplicada (IPEA), 2017. Available from: www.ipeadata.gov.br/default.aspx Accessed: May 16, 2017.

Kinge JM, Steingrímsdóttir OA, Moe JO, Skirbekk V, Naess O, Strand BH, 2015. Educational differences in life expectancy over five decades among the oldest old in Norway. Age Ageing 44:1040-5.

Kolahdooz F, Nader F, Yi KJ, Sharma S, 2015. Understanding the social determinants of health among Indigenous Canadians: Priorities for health promotion policies and actions. Glob Health Action 8:27968.

Lin R-T, Chen Y-M, Chien L-C, Chan C-C, 2012. Political and social determinants of life expectancy in less developed countries: a longitudinal study. BMC Public Health 12:85.

Lima-Costa MF, De Oliveira C, MacInko J, Marmot M, 2012. Socioeconomic inequalities in health in older adults in Brazil and England. Am J Public Health 102:1535-41.

Mathers CD, Stevens GA, Boerma T, White RA, Tobias MI, 2015. Causes of international increases in older age life expectancy. Lancet 385:540-8.

Marmot M, 2005. Social determinants of health inequalities. Lancet 365:1099-104.

Marmot M, 2016. Brazil: rapid progress and the challenge of inequality. Int J Equity Health 15:177.

Ministério da Saúde, Brasil, 2007. Sistemas de informações geográficas e análise espacial na saúde pública. 1st ed. Brasília: Secretaria de Vigilância em Saúde/Fundação Oswaldo Cruz. 148 pp.

Mondal MNI, Shitan M, 2014. Relative importance of demographic, socioeconomic and health factors on life expectancy in lowand lower-middle-income countries. J Epidemiol 24:117-24. 
Moran PAP, 1948. The interpretation of statistical maps. J Royal Statist Soc 10:243-51.

Rasella D, Machado DB, Castellanos MEP, Paim J, Szwarcwald CL, Lima D, Magno L, Pedrana L, Medina MG, Penna GO, Barreto ML, 2016. Assessing the relevance of indicators in tracking social determinants and progress toward equitable population health in Brazil. Glob Health Action 9:29042.

Rede Interagencial de Informações para Saúde (RIPSA), 2009. Informe de situação e tendências: demografia e saúde. 1st ed. Brasília-DF: OPAS.

Rivera-Hernandez M, Yamashita T, Kinney JM, 2015. Identifying naturally occurring retirement communities: a spatial analysis. J Gerontol B Psychol Sci Soc Sci 70:619-27.

Rodrigues NO, Neri AL, 2012. Vulnerabilidade social, individual e programática em idosos da comunidade: dados do estudo FIBRA, Campinas, SP, Brasil. Cien Saude Coletiva 17:212939.
Shapiro SS, Wilk MB, 1965. An analysis of variance test for normality. Biometrika 52:591-611.

Sudharsanan N, 2017. The association between socioeconomic status and adult mortality in a developing country: evidence from a nationally representative longitudinal survey of Indonesian adults. J Gerontol Ser B 1-12.

Suzman R, Beard JR, Boerma T, Chatterji S, 2015. Health in an ageing world - What do we know? Lancet 385:484-6.

Valentine NB, Bonsel GJ, 2016. Exploring models for the roles of health systems' responsiveness and social determinants in explaining universal health coverage and health outcomes. Glob Health Action 9.

Veras R, 2009. Envelhecimento populacional contemporâneo: demandas, desafi os e inovações - Population aging today: demands, challenges and innovations. Rev Saude Publica 43:548-54. 